\title{
Papers
}

\section{Relations of income inequality and family income to chronic medical conditions and mental health disorders: national survey}

\author{
Roland Sturm, Carole Roan Gresenz
}

\begin{abstract}
Objectives To analyse the relation between geographical inequalities in income and the prevalence of common chronic medical conditions and mental health disorders, and to compare it with the relation between family income and these health problems.

Design Nationally representative household

telephone survey conducted in 1997-8.

Setting 60 metropolitan areas or economic areas of the United States.

Participants 9585 adults who participated in the community tracking study.

Main outcome measures Self report of 17 common chronic medical conditions; current depressive disorder or anxiety disorder assessed by clinical screeners.

Results A strong continuous association was seen between health and education or family income. No relation was found between income inequality and the prevalence of chronic medical problems or depressive disorders and anxiety disorders, either across the whole population or among poorer people. Only self reported overall health, the measure used in previous studies, was significantly correlated with inequality at the population level, but this correlation disappeared after adjustment for individual characteristics. Conclusions This study provides no evidence for the hypothesis that income inequality is a major risk factor for common disorders of physical or mental health.
\end{abstract}

\section{Introduction}

The "income inequality hypothesis" says that disparities in income among members of a community affect their health and, specifically, that economically egalitarian communities or societies have better health outcomes than more unequal communities. ${ }^{1-3}$ Some proponents argue that inequality in incomes is a stronger determinant of health than the income of individuals or families. ${ }^{1}$

Initial support for the income inequality hypothesis came from aggregate level studies of total mortality or cause specific mortality. ${ }^{1-10}$ More recent studies at the level of the individual confirm the positive correlation between inequality and self rated health or mortality at the population level, but show mixed results once individual characteristics are included in the analysis. ${ }^{11-17}$ Health status was usually measured by the question, "In general, would you say that your health is excellent, very good, good, fair, or poor?" Three studies also measured psychological distress. ${ }^{15} 1718$

This study re-examines the income inequality hypothesis with measures of health that reflect the presence or absence of 17 chronic physical conditions and specific disorders of mental health, by using data from a survey carried out in 1997-8 in 60 metropolitan or economic areas across the United Sates. We discuss how the relation between income inequality and these physical and mental health conditions compares with the relation between family income and health.

\section{Methods}

\section{Sources of data}

"Healthcare for Communities" is a household telephone survey clustered in 60 randomly selected metropolitan areas or economic areas of the United States; it was carried out in 1997-8..$^{19}$ The surveyors reinterviewed a stratified random sample of 9585 participants of the community tracking study ${ }^{20}$ and achieved a response rate of $64 \%$. This analysis focuses on 8235 respondents living in the 60 sites for which measures of income inequality are available (1337 respondents lived outside the 60 sites). We derived weights on the basis of the inverse of the probability of selection, non-response, and households without a telephone. Descriptions of the study design have been published. ${ }^{19} 20$

\section{Outcome measures}

For comparability with previous studies we analysed the self reported general health status of respondents and created an indicator for a response of poor or fair (population weighted mean $=16.3 \%$ ). ${ }^{14}{ }^{17}$ Numbers presented were calculated by using sampling weights to provide nationally representative estimates

Our measure of mental health considered four psychiatric disorders-major depressive disorder, dysthymic disorder, panic disorder, and generalised anxiety disorder-which we assessed by using the composite international diagnostic interview, short form,

\author{
RAND, 1700 Main \\ Street, Santa \\ Monica, CA 90401, \\ USA \\ Roland Sturm \\ senior economist \\ RAND, 1200 South \\ Hayes Street, \\ Arlington, VA \\ 22202, USA \\ Carole Roan \\ Gresenz \\ economist \\ Correspondence to: \\ R Sturm \\ sturm@rand.org \\ BMJ 2002;324:1-5
}


plus role limitation for panic disorder. ${ }^{21-23}$ The weighted population estimate is $13.2 \%$ for at least one of the four disorders and $10.5 \%$ for at least one of the two depressive disorders (major depressive disorder and dysthymic disorder).

We assessed physical health from answers to questions about 17 chronic health conditions: asthma; diabetes; hypertension; arthritis; a physical disability; trouble breathing; cancer; a neurological condition; stroke or paralysis; angina, heart failure, or coronary artery disease; chronic back problems; stomach ulcer; chronic liver disease; migraine or chronic severe headaches; chronic bladder problems; chronic gynaecological problems (women only); and unspecified chronic pain. We report results for the overall number of conditions and for the more common individual conditions or conditions that may have psychosocial components. Weighted percentages are $26.9 \%$ for at least one of three pain conditions (migraine or chronic severe headaches, back pain, other unspecified chronic pain); $22.7 \%$ for arthritis; $16.6 \%$ for hypertension; $8.9 \%$ (of women) for gynaecological problems; $6.1 \%$ for diabetes; $4.3 \%$ for angina, heart failure, or coronary heart disease; and 3.9\% for trouble breathing.

\section{Income inequality, individual income, and other independent variables}

We calculated income inequality at site level from the community tracking study. For the sensitivity analysis we also used Kahn et al's state level inequality measures based on the 1990 census $^{17}$ and three of Mellor and Milyo's $^{16}$ state measures based on the current population surveys. The results shown are based on the Gini coefficient, ${ }^{24-26}$ which ranges from 0.38 to 0.54 across the 60 communities. This is higher than the $0.27-0.35$ range found in a British mental health study, indicating higher levels of inequality. ${ }^{18}$

Income at the individual level was measured as family income, which includes earnings from work, transfer income, and other sources. The survey asked about each major component of income separately, and respondents were asked to respond with actual dollar amounts. Unfolding follow up brackets were adopted to reduce item non-response-this method allows partial information to be obtained about missing items when respondents are unwilling to provide a more detailed answer. ${ }^{27}$ The tables classify respondents by fifths of income on the basis of the national distribution of income (rather than fifths of the sample), resulting in larger low income groups because the study oversampled poorer people.

We also used age, sex, race or ethnicity, and size of family to adjust for confounding factors in the statistical analyses.

\section{Analyses}

We grouped respondents by fifths of family income and by community level inequality and calculated a weighted mean for the prevalence of each condition in each group. We tested the association between prevalence of medical conditions and family income or inequality by using individual level logistic regressions with an indicator of a health condition as the dependent variable. We tested the association both with and without adjustment for other individual level sociodemographic variables. $\mathrm{P}$ values for tests of associations given in the final two columns are based on tests using continuously measured family income or inequality. We also allowed for non-linear effects of inequality on health outcomes by including dummy variables for each fifth of inequality and with a quadratic function of inequality, but the results were robust to the alternative specifications and are not reported. We weighted regressions and nonparametrically adjusted standard errors by using the Huber-White correction as implemented in the cluster option in Stata 6.0 to account for the sampling design. In the sensitivity analyses, we substituted income adjusted for education or family size for total family income and used state level inequality measures instead of site level inequality. The figures are based on regression models with sociodemographic variables and dummy variables for each fifth of site income inequality.

\section{Results}

Table 1 confirms the strong social gradient in health by income. Most conditions showed a continuous relation between prevalence and income across most of the income range. However, the magnitude of the drop in the prevalence of health problems tended to be largest from the lowest fifth to the next fifth. The final column in the table gives $\mathrm{P}$ values from two tests of association between the prevalence of the condition and family income. The first value reports the results when socio-

Table 1 Health status by fifths of income. Values are means (SD), given as percentages, unless stated otherwise

\begin{tabular}{|c|c|c|c|c|c|c|c|}
\hline \multirow[b]{2}{*}{ Health status } & \multirow{2}{*}{$\begin{array}{l}\text { Poorest fifth } \\
(\mathrm{n}=2139)\end{array}$} & \multirow{2}{*}{$\begin{array}{l}\text { Below middle } \\
\text { fifth }(n=1834)\end{array}$} & \multirow{2}{*}{$\begin{array}{l}\text { Middle income } \\
\text { fifth }(n=1590)\end{array}$} & \multirow{2}{*}{$\begin{array}{l}\text { Above middle } \\
\text { fifth }(n=1468)\end{array}$} & \multirow{2}{*}{$\begin{array}{l}\text { Highest income } \\
\text { fifth }(n=1204)\end{array}$} & \multicolumn{2}{|c|}{$P$ value for income gradient } \\
\hline & & & & & & Unadjusted & Adjusted * \\
\hline Self reported poor or fair health & $27.8(44.8)$ & $17.5(38.0)$ & $11.6(32.0)$ & $5.2(22.2)$ & $5.2(22.2)$ & $<0.001$ & $<0.001$ \\
\hline Mean (SD) No of chronic conditions & $1.80(1.97)$ & $1.32(1.56)$ & $1.03(1.40)$ & $0.87(1.23)$ & $0.87(1.22)$ & $<0.001$ & $<0.001$ \\
\hline \multicolumn{8}{|l|}{ Prevalence of chronic conditions: } \\
\hline Depressive disorder or anxiety disorder & $18.2(38.6)$ & $13.2(33.9)$ & $11.2(31.6)$ & $10.0(30.0)$ & $7.4(26.1)$ & $<0.001$ & 0.002 \\
\hline Depressive disorder & $14.9(36.6)$ & $10.6(30.8)$ & $8.3(27.6)$ & $8.5(27.8)$ & $5.5(22.7)$ & $<0.001$ & 0.003 \\
\hline $\begin{array}{l}\text { Pain condition (including back pain, chronic headache, } \\
\text { other non-specified chronic pain problem) }\end{array}$ & $35.4(47.8)$ & $28.3(45.1)$ & $25.4(43.6)$ & $22.7(41.9)$ & $22.5(41.7)$ & 0.019 & 0.055 \\
\hline High blood sugar or diabetes & $10.3(30.4)$ & $8.2(27.4)$ & $6.2(24.0)$ & $3.6(18.5)$ & $2.3(15.0)$ & 0.001 & 0.026 \\
\hline Hypertension or high blood pressure & $25.0(43.8)$ & $18.9(39.2)$ & $13.2(33.8)$ & $11.5(31.9)$ & $13.2(33.8)$ & 0.002 & $>0.1$ \\
\hline Arthritis or rheumatism & $33.8(47.3)$ & $26.4(44.1)$ & $21.1(40.9)$ & $16.0(36.7)$ & $16.1(36.7)$ & $<0.001$ & $<0.001$ \\
\hline Trouble breathing, emphysema, or chronic lung disease & $7.6(26.5)$ & $4.0(19.7)$ & $3.8(19.2)$ & $2.0(14.1)$ & $1.7(12.8)$ & $<0.001$ & 0.001 \\
\hline Angina, heart failure, or coronary heart disease & $8.2(27.4)$ & $5.5(22.8)$ & $2.9(16.7)$ & $1.9(13.7)$ & $3.2(17.6)$ & 0.004 & 0.082 \\
\hline $\begin{array}{l}\text { Chronic gynaecological problem, such as severe cramps } \\
\text { or heavy bleeding (women only) }\end{array}$ & $7.8(26.8)$ & $11.4(31.9)$ & $9.1(28.8)$ & $9.0(28.7)$ & $7.0(25.5)$ & $>0.1$ & 0.018 \\
\hline
\end{tabular}

*Adjusted for age, sex, race or ethnicity, and family composition. 
Table 2 Health status by fifths of income. Adjusted income (family income/(adult +0.5 dependant)). Values are means (SD), given as percentages, unless stated otherwise

\begin{tabular}{|c|c|c|c|c|c|c|c|}
\hline & \multirow{2}{*}{$\begin{array}{l}\text { Poorest fifth } \\
(\mathrm{n}=2101)\end{array}$} & \multirow{2}{*}{$\begin{array}{l}\text { Below middle } \\
\text { fifth }(n=1853)\end{array}$} & \multirow{2}{*}{$\begin{array}{l}\text { Middle income } \\
\text { fifth }(n=1613)\end{array}$} & \multirow{2}{*}{$\begin{array}{l}\text { Above middle } \\
\text { fifth }(n=1454)\end{array}$} & \multirow{2}{*}{$\begin{array}{l}\text { Highest income } \\
\text { fifth }(n=1194)\end{array}$} & \multicolumn{2}{|c|}{$P$ value for income gradient } \\
\hline & & & & & & Unadjusted & Adjusted \\
\hline Self reported poor or fair health & $26.4(44.1)$ & $17.5(38.0)$ & $11.5(32.0)$ & $5.2(22.3)$ & $6.8(25.1)$ & $<0.001$ & $<0.001$ \\
\hline Mean (SD) No of chronic conditions & $1.71(1.94)$ & $1.32(1.56)$ & $1.00(1.43)$ & $0.91(1.21)$ & $0.94(1.28)$ & $<0.001$ & $<0.001$ \\
\hline Depressive disorder or anxiety disorder & $16.6(37.2)$ & $13.4(34.1)$ & $11.2(31.6)$ & $9.6(29.5)$ & $9.2(29.0)$ & $<0.001$ & 0.002 \\
\hline Depressive disorder & $13.5(34.1)$ & $10.7(30.9)$ & $8.8(28.3)$ & $7.7(26.6)$ & $7.2(25.9)$ & $<0.001$ & 0.002 \\
\hline $\begin{array}{l}\text { Pain condition (including back pain, chronic headache, } \\
\text { other non-specified chronic pain problem) }\end{array}$ & $34.8(47.6)$ & $28.6(45.2)$ & $24.0(42.7)$ & $21.9(41.4)$ & $24.9(43.2)$ & 0.038 & 0.043 \\
\hline High blood sugar or diabetes & $9.3(29.0)$ & $8.9(28.4)$ & $6.5(24.7)$ & $2.4(15.6)$ & $3.4(18.2)$ & 0.045 & $>0.1$ \\
\hline Hypertension or high blood pressure & $24.3(42.9)$ & $18.7(39.0)$ & $13.0(33.7)$ & $13.2(33.9)$ & $13.5(34.2)$ & 0.034 & $>0.1$ \\
\hline Arthritis or rheumatism & $32.0(46.7)$ & $28.3(45.0)$ & $17.6(38.1)$ & $18.2(38.6)$ & $17.5(38.0)$ & $<0.001$ & $<0.001$ \\
\hline Trouble breathing, emphysema, or chronic lung disease & $7.9(26.9)$ & $4.5(20.7)$ & $3.0(17.0)$ & $3.1(17.4)$ & $2.0(13.9)$ & $<0.001$ & 0.001 \\
\hline Angina, heart failure, or coronary heart disease & $8.2(27.4)$ & $4.9(21.7)$ & $3.8(19.1)$ & $1.7(12.8)$ & $3.5(18.4)$ & 0.026 & 0.071 \\
\hline $\begin{array}{l}\text { Chronic gynaecological problem, such as severe cramps } \\
\text { or heavy bleeding (women only) }\end{array}$ & $7.9(27.0)$ & $9.8(29.8)$ & $10.9(31.1)$ & $8.2(27.4)$ & $7.6(26.6)$ & $>0.1$ & 0.020 \\
\hline
\end{tabular}

demographic characteristics were not included in the regression, and the second value reflects a regression adjusted for age group, sex, race or ethnicity, and composition of family. The association between family income and prevalence was highly significant for almost all conditions. The overall picture was identical when we stratified results by income adjusted for family size or educational achievement (less than high school, high school, some college, college degree; results not shown). Table 2 shows the results obtained when we made adjustments for household composition by dividing family income by the square root of the number of household members, where dependants have a weight of 0.5 . The results do not differ from those in table 1 .

Table 3 shows the prevalence of health problems by fifth of community level income inequality. Consistent with previous studies, we found a highly significant $(\mathrm{P}<0.01)$ association between high income inequality and the probability that a person reports being in poor or fair health, although the finding was not robust to adjustment for other sociodemographic factors. Except for this self reported health measure, however, there was no discernible pattern in health outcomes by income inequality. A third of the conditions were most prevalent in communities with average income inequality, and three health problems (depression, chronic pain, and asthma) were most prevalent in communities with low income inequality (bottom two fifths). With the exception of chronic gynaecological problems, we found no significant association between any specific health condition-chronic, mental, or otherwise-and income inequality (including conditions not shown). Even the significant result for gynaecological problems disappeared when individual sociodemographic variables were taken into account. In contrast, the highest prevalence for every condition occurred in one of the two poorest fifths as stratified by family income.

Figures 1 and 2 show the same relations (between income inequality and health conditions and between family income and health conditions) after adjustment for differences in sociodemographic characteristics.

Table 4 summarises the results from a subset of the sensitivity tests that we conducted, all based on regression models controlling for other sociodemographic variables. When we substituted income adjusted for size of family or level of education for family income, a strong and highly significant social gradient remained. This was also the case for men and women separately (results not shown). Income inequality, on the other hand, had no effect, regardless of whether it was measured by the state level Gini coefficient, the coefficient of variation, the share of income held by the top $50 \%$ of the income distribution, or the ratio of the 90 th to 10 th centiles of the income. Nor did

\begin{tabular}{|c|c|c|c|c|c|c|c|}
\hline \multirow[b]{2}{*}{ Health status } & \multirow{2}{*}{$\begin{array}{l}\text { Lowest } \\
\text { inequality } \\
\text { (n=2137) }\end{array}$} & \multirow{2}{*}{$\begin{array}{c}\text { Second lowest } \\
\text { inequality } \\
(\mathrm{n}=1678)\end{array}$} & \multirow{2}{*}{$\begin{array}{c}\text { Middle } \\
\text { inequality } \\
(n=1559)\end{array}$} & \multirow{2}{*}{$\begin{array}{l}\text { Above middle } \\
\text { inequality } \\
(n=1538)\end{array}$} & \multirow{2}{*}{$\begin{array}{l}\text { Highest } \\
\text { inequality } \\
(n=1323)\end{array}$} & \multicolumn{2}{|c|}{$P$ value for income gradient } \\
\hline & & & & & & Unadjusted & Adjusted $^{*}$ \\
\hline Self reported poor or fair health & $13.6(34.3)$ & $9.4(29.1)$ & $14.6(35.3)$ & $14.0(34.7)$ & $17.5(38.0)$ & 0.006 & $>0.1$ \\
\hline Mean (SD) No of chronic conditions & $1.28(1.66)$ & $1.05(1.40)$ & $1.27(1.53)$ & $1.07(1.56)$ & $1.30(1.53)$ & $>0.1$ & $>0.1$ \\
\hline \multicolumn{8}{|l|}{ Prevalence of chronic conditions: } \\
\hline Depressive disorder or anxiety disorder & $12.1(32.6)$ & $12.7(33.3)$ & $12.8(33.3)$ & $10.6(30.8)$ & $11.9(32.4)$ & $>0.1$ & $>0.1$ \\
\hline Pain condition & $28.9(45.3)$ & $23.3(42.2)$ & $27.0(44.4)$ & $27.5(44.7)$ & $28.4(45.1)$ & $>0.1$ & $>0.1$ \\
\hline Asthma & $7.6(26.6)$ & $5.3(22.3)$ & $7.4(26.2)$ & $6.4(24.4)$ & $7.0(25.5)$ & $>0.1$ & $>0.1$ \\
\hline High blood sugar or diabetes & $6.8(25.1)$ & $6.0(23.8)$ & $6.8(25.1)$ & $4.3(20.3)$ & $7.4(26.1)$ & $>0.1$ & $>0.1$ \\
\hline Hypertension or high blood pressure & $17.1(37.7)$ & $14.8(35.6)$ & $20.0(40.0)$ & $13.2(33.9)$ & $19.4(39.5)$ & $>0.1$ & $>0.1$ \\
\hline Arthritis or rheumatism & $24.2(42.8)$ & $22.4(41.7)$ & $25.4(43.5)$ & $20.1(40.1)$ & $21.9(41.4)$ & 0.095 & $>0.1$ \\
\hline Trouble breathing, emphysema, or chronic lung disease & $3.9(19.4)$ & $3.6(18.7)$ & $5.3(22.5)$ & $2.9(16.7)$ & $3.9(19.4)$ & $>0.1$ & $>0.1$ \\
\hline Angina, heart failure, or coronary heart disease & $5.0(21.9)$ & $3.8(19.1)$ & $5.6(23.0)$ & $3.8(19.1)$ & $3.6(18.5)$ & $>0.1$ & $>0.1$ \\
\hline
\end{tabular}

*Adjusted for age, sex, race or ethnicity, and family composition. 


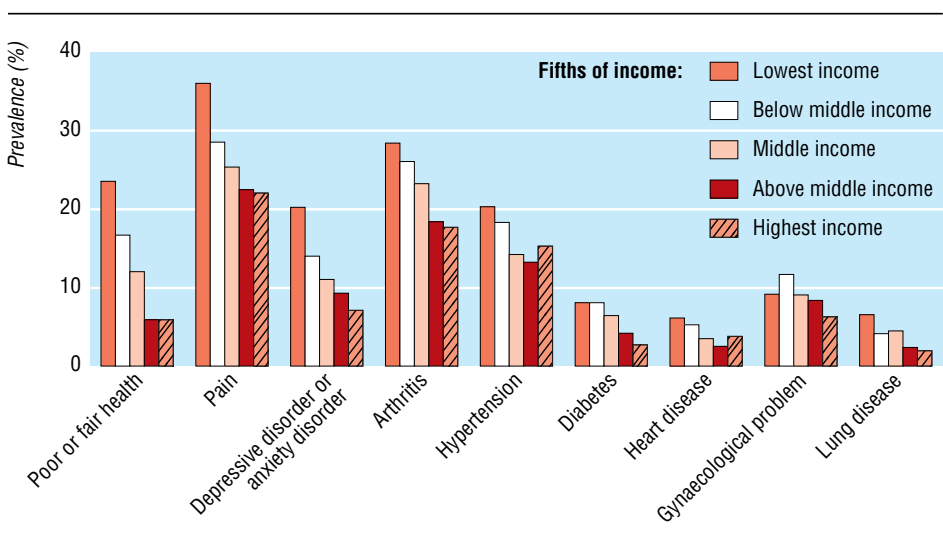

Fig 1 Adjusted prevalence of chronic conditions by fifths of family income

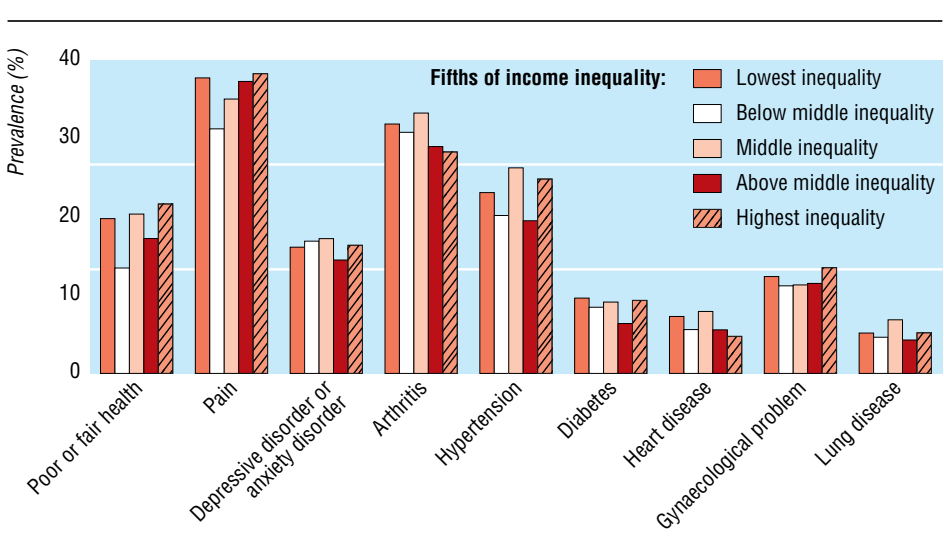

Fig 2 Adjusted prevalence of chronic conditions by fifths of income inequality

we find any effect of inequality when we used subsets of data for poorer respondents, richer respondents, women only, men only, minorities only, or other combinations. Among more than 200 regression models on the full sample that used income inequality as the primary explanatory variable and had sociodemographic controls, only one result was significant at $\mathrm{P}<0.01$, but it had the wrong sign (higher state level inequality was associated with a reduced prevalence of arthritis or rheumatism). We paid particular attention to potential effects of inequality among people with lower incomes (a "weak" income inequality hypothesis) because Kahn et al found significant effects on mental health status among poor women. ${ }^{17}$ Our data did not replicate their finding, even when we used their measure of income inequality.

\section{Discussion}

The relation between income inequality and health has been at the centre of a substantial amount of research, but the measures of health status that have been analysed to date have largely been limited to self reported health status or mortality in the case of physical health, and depressive symptoms or psychological distress for mental health. To our knowledge, this study is the first to explore the association between income inequality and several specific physical conditions as well as particular mental health disorders. Although our data confirm the association between income inequality and poor or fair self reported health, no similar relation exists between income inequality and depressive disorders or anxiety disorders or any of the medical conditions assessed, either at the population level or among people with lower incomes, wealthier people, women, or men. On the other hand, family income and education, which may reflect rank in the social hierarchy, are strongly related to health. Their effects are not confined to differences between the lowest income group and other groups (which would point towards material deprivation as an explanation) but show a gradient that flattens well above the median income level. This finding is similar to that of the Whitehall studies of British civil servants, where social gradients in morbidity and mortality ran from the bottom to the top of the hierarchy. ${ }^{28-30}$

The sample size of this study provides good statistical power to detect differences between fifths of inequality up to $75 \%$ smaller than the estimated differences between fifths of family income. Smaller inequality effects (that is, more than $75 \%$ smaller than the estimated differences between fifths of income) may not be detectable, however. Measurement error in the site level inequality measure could also bias estimates downward, but the results were unchanged for alternative inequality measures at the state level.

Although we found no empirical support for the hypothesis that income inequality affects mortality or self rated health status through higher rates of specific

Table 4 Sensitivity tests ( $P$ values) for subgroups and other explanatory variables, based on regression model including sociodemographic variables

\begin{tabular}{|c|c|c|c|c|c|}
\hline Dependent variable & $\begin{array}{l}\text { Education } \\
\text { (4 levels) }\end{array}$ & $\begin{array}{l}\text { State inequality } \\
\text { (Gini reported by } \\
\text { Kahn et al) }{ }^{17}\end{array}$ & $\begin{array}{c}\text { State inequality } \\
\text { (poorest two fifths } \\
\text { only) }\end{array}$ & $\begin{array}{c}\text { Site inequality } \\
\text { (poorest two fifths } \\
\text { only) }\end{array}$ & $\begin{array}{c}\text { State inequality } \\
\text { (poorest two fifths, } \\
\text { women only) }\end{array}$ \\
\hline Self reported poor or fair health & $<0.001$ & $>0.1$ & $>0.1$ & $>0.1$ & $>0.1$ \\
\hline No of chronic conditions & $<0.001$ & $>0.1$ & $>0.1$ & $>0.1$ & $>0.1$ \\
\hline Depressive disorder or anxiety disorder & $<0.001$ & $>0.1$ & $>0.1$ & $>0.1$ & 0.095 \\
\hline Depressive disorder & $<0.001$ & $>0.1$ & $>0.1$ & $>0.1$ & $>0.1$ \\
\hline Pain condition & 0.001 & $>0.1$ & $>0.1$ & 0.050 & NS \\
\hline High blood sugar or diabetes & $<0.001$ & $>0.1$ & $>0.1$ & $>0.1$ & $>0.1$ \\
\hline Hypertension or high blood pressure & $<0.001$ & $>0.1$ & $>0.1$ & $>0.1$ & $>0.1$ \\
\hline Arthritis or rheumatism & $<0.001$ & $\begin{array}{l}<0.001, \text { but } \\
\text { "wrong" sign }\end{array}$ & $>0.1$ & $>0.1$ & $>0.1$ \\
\hline Trouble breathing, emphysema, or chronic lung disease & 0.002 & $>0.1$ & $>0.1$ & $>0.1$ & $>0.1$ \\
\hline Angina, heart failure, or coronary heart disease & $<0.001$ & $>0.1$ & $>0.1$ & $>0.1$ & $>0.1$ \\
\hline $\begin{array}{l}\text { Chronic gynaecological problems, such as severe } \\
\text { cramps or heavy bleeding (women only) }\end{array}$ & 0.010 & $>0.1$ & $>0.1$ & $>0.1$ & $>0.1$ \\
\hline
\end{tabular}




\section{What is already known on this topic}

Several studies have found a relation between income inequality and self reported health or mortality

\section{What this study adds}

There is a strong social gradient in health, as measured by the prevalence of chronic medical conditions and specific mental health disorders, by income or education

No such association is seen between income inequality and health

medical conditions, the results do not necessarily contradict previously reported associations between income inequality and self rated health status or mortality. Factors linking income inequality to health may include the severity of disorder, the probability that a person receives a diagnosis conditional on having a disorder, and the way in which having a disorder determines people's perceptions of their health. But some of these factors are likely to be influenced by environmental factors other than income inequality, including state policies and healthcare infrastructure, that may be unrelated to income distribution. It seems premature to conclude that income inequality itself is an important risk factor for poor health, and the results highlight the need to better understand the psychological and physiological pathways through which the social environment affects health.

We thank Michael Schoenbaum and Jürgen Unützer for comments, Jennifer Mellor and Jeff Milyo for providing their measures of income inequality, and Lingqi Tang and Fuan-Yue Kung for assistance with programming.

Contributors: RS and CRG had the idea for the study, performed the main statistical analysis, and wrote the paper They are the guarantors.

Funding: Robert Wood Johnson Foundation, which funded the healthcare for communities survey, and the National Institute of Mental Health (R01-MH62124)

Competing interests: None declared.

1 Wilkinson RG. Unhealthy societies: the affiction of inequality. London: Routledge, 1996

2 Lynch JW, Smith GD, Kaplan GA, House JS. Income inequality and mortality: importance to health of individual income, psychosocial environment, or material conditions. BMJ 2000;320:1200-4.

3 Marmot M, Wilkinson RG. Psychosocial and material pathways in the relation between income and health. BMJ 2001;322:1233-6.
4 Rodgers GB. Income and inequality as determinants of mortality: an international cross-section analysis. Population Studies 1979;33:343-51.

5 Flegg A. Inequality of income, illiteracy and medical care as determinant of infant mortality in developing countries. Population Studies 1982;36: 441-58.

6 Le Grand J. Inequality in health: some international comparisons. Eur Econ Rev 1987;31:182-91.

7 Wilkinson RG. Income distribution and life expectancy. $B M$ J 1992;304:165-8.

8 Kaplan GA, Pamuk E, Lynch JW, Cohen RD, Balfour JL. Income inequality and mortality in the United States: analysis of mortality and potential pathways. $B M J$ 1996:312:99-1003.

9 Kennedy BP, Kawachi I, Prothrow-Stith D. Income distribution and mortality: cross-sectional ecological study of the Robin Hood index in the United States. BMJ 1996;312:1004-7.

10 Mellor JM, Milyo J. Reexamining the evidence of an ecological association between income inequality and health. $J$ Health Polit Policy Law 2001;26:487-522.

11 Fiscella K, Franks P. Poverty or income inequality as predictor of mortality: longitudinal cohort study. BMJ 1997;314:1724-7.

12 Daly MC, Duncan GJ, Kaplan GA, Lynch JW. Macro-to-micro links in the relation between income inequality and mortality. Milbank $Q$ 1998;76:303-4, 315-39.

13 Kennedy BP, Kawachi I, Glass R, Prothrow-Stith D. Income distribution, socioeconomic status, and self rated health in the United States. $B M J$ 1998:317:917-21.

14 Soobader MJ, LeClere FB. Aggregation and the measurement of income inequality: effects on morbidity. Soc Sci Med 1999;48:733-44.

15 Fiscella K, Franks P. Individual income, income inequality, health, and mortality: what are the relationships? Health Serv Res 2000;34:307-18

16 Mellor JM, Milyo J. Income inequality and health status in the United States: evidence from the current population survey. J Hum Resources (in press).

17 Kahn RS, Wise PH, Kennedy BP, Kawachi I. State income inequality, household income, and maternal mental and physical health: cross sectional national survey. BMJ 2000;321:1311-5.

18 Weich S, Lewis G, Jenkins SP. Income inequality and the prevalence of common mental disorders in Britain. Br J Psychiatry 2001;178:222-7.

19 Sturm R, Gresenz C, Sherbourne CD, Minnium K, Klap R, Bhattacharya $\mathrm{J}$, et al. The design of healthcare for communities: a study of health care delivery for alcohol, drug abuse, and mental health conditions. Inquiry 1999;36:221-33.

20 Kemper P, Blumenthal D, Corrigan JM, Cunningham PJ, Felt SM, Grossman JM, et al, The design of the community tracking study: a longitudinal study of health system change and its effect on people. Inquiry nal study of hea

21 Kessler RC, Andrews G, Mroczek D, Ustun B, Wittchen HU. The World Health Organization composite international diagnostic interview shortform (CIDI-SF). Int J Methods Psychiatric Res 1998;7:171-85.

22 Ware JE, Kosinski M, Keller SD. A 12-item short-form health survey: construction of scales and preliminary tests of reliability and validity. Med Care 1996;34:220-33

23 World Health Organization. Composite international diagnostic interview (version 2.0). Geneva, Switzerland: WHO, 1995

24 Sen A. On economic inequality. Oxford: Oxford University Press, 1973

25 Cowell FA. Measuring inequality. Oxford: Allan, 1977.

26 Jones AF, Weinberg DH. The changing shape of the nation's income distribution: 1947-1998. Current Population Reports P60-204, Bureau of the Census, 2000.

27 Juster FT, Smith JP. Improving the quality of economic data: lessons from the HRS and AHEAD. J Am Stat Assoc 1997;92:1268-78.

28 Marmot MG, Shipley MJ, Rose G. Inequalities in death-specific explanations of a general pattern? Lancet 1984;1:1003-6.

29 Marmot MG, Shipley MJ. Do socioeconomic differences in mortality persist after retirement? 25 year follow up of civil servants from the first Whitehall study. BMJ 1996;313:1177-80.

30 Marmot MG, Davey Smith G, Stansfeld S, Patel C, North F, Head J, et al. Health inequalities among British civil servants: the Whitehall II study. Lancet 1991;337:1387-93.

(Accepted 17 September 2001) 